\title{
Freud 150 años: Maestro de la sospecha
}

\author{
Gustavo Figueroa C. ${ }^{1}$
}

La conmemoración de los 150 años de su nacimiento ha despertado en el mundo occidental la sensación de que por fin se ha cumplido el ciclo largamente pronosticado de auge y caída de Freud (1856-1939). De ahí el sepulcral silencio que ha acompañado esta fecha, a diferencia de las celebraciones casi excesivas de su centenario en 1956.

La situación de Freud es empero harto más compleja en nuestra cultura. En primer término, él se ha constituido en un clima de opinión. Ninguna persona de nuestro siglo XXI puede eludir hablar de inconsciente, complejo, sexualidad, determinismo de la infancia, deseo del bebé por la madre, amor edípico, interpretación de los sueños, etc. Crea en todo esto o lo abomine visceralmente, piense que es pura charlatanería o adhiera con la fe del carbonero. No importa, porque se ha convertido en creencia social, en la creencia de occidente que va más allá de nuestras opiniones personales e ideas particulares porque, como dice O rtega y Gasset, se tienen ideas pero en las creencias se está y ellas nos sostienen.

Segundo y contrariamente, Freud ha sido implacable en demoler todos nuestros pensamientos y certidumbres más queridos. Nuestra cultura oculta pasiones prohibidas que paradójicamente han hecho posible su surgimiento, el espíritu es una máscara bien pintada pero que silencia con dureza nuestras necesidades primarias, el avance histórico se ha generado gracias al sacrificio inmisericorde de nuestra estirpe animal que pugna por emerger creando un malestar que ha llegado al límite de lo tolerable, la religión es una ilusión que sólo en apariencia nos ayuda a soportar las cargas de la existencia, la muerte la llevamos dentro de nosotros mismos como parte inherente a nuestra condición. Partidario como pocos de la ciencia, Freud se encuentra empero entre los detractores acérrimos del progreso indefinido proclamado con soberbia por los hombres de ciencia desde la Ilustración hasta hoy, recordándonos que jamás podremos escapar a la despiadada ananké [destino].

En tercer término, nosotros, cuyo mayor orgullo es ser la única criatura de la creación que es racional, que posee la razón, nos desconocemos a nosotros mismos. Nos mentimos, engañamos, falsificamos, edulcoramos nuestra realidad interior, con delicados o toscos afeites nos embadurnamos para escapar a nuestras más propias y desazonantes posibilidades de ser. Si alguien ha contribuido a cuestionar el concepto de subjetividad o cogito heredero de toda la filosofía moderna ese ha sido Freud.

Cuarto, ha trasformado nuestra sociedad en un inmenso hospital. Lo sano se diferencia de lo enfermo sólo cuantitativa pero no cualitativamente, no hay un corte inequívoco entre el soñar y el alucinar, los conflictos de los neuróticos son nuestros conflictos sólo que aquellos son más inconscientes o han sido peor manejados o han conducido a mayor autodestructividad, los mecanismos que producen los errores de la vida cotidiana son los mismos que generan los síntomas psicosomáticos, la perversión es el negativo de las neuro-

1 Editor Psiquiatría, Revista Chilena de Neuro Psiquiatría.

Departamento de Psiquiatría, Escuela de Medicina. Universidad de Valparaíso. 
sis, los niños normales son polimorfos perversos, los deseos asesinos de los psicópatas anidan por igual en nuestros pechos. Como diría Foucault, lo anormal explica lo normal y no lo inverso.

Quinto, la psicología del sentido común del oficinista decente o del tendero de la esquina encontró su fundamento científico en Freud. Sin perder la ingenuidad que tienen las verdades de la gente corriente, Freud les entregó un sentido a estas verdades que impacta cuando se siguen sus razonamientos meticulosos, sutiles y perspicaces. Por tomar un ejemplo concreto, pocos lectores se pueden escapar al hechizo que produce comprender que los reproches que se dirigen a sí mismas las personas afectadas por un duelo reciente en verdad son reprimendas feroces que se lanzan a la persona muerta producto de la ambivalencia de las relaciones amorosas.

Sexto y último, la psiquiatría no es en absoluto la misma antes y después de Freud, como diría Jaspers, él ha sido un acontecimiento axial. Cualesquiera que sean los defectos, carencias, errores, mitologías, falsedades, elisiones, mistificaciones, cuentos de hadas, delirios, narcisismos del psiquiatra de Viena. Nadie como él ha ayudado a modificar la estructura, sentido y alcances de la teoría y práctica de la psiquiatría. Es muy posible que otros psiquiatras hayan descubierto hechos más decisivos o científicamente probados que él, pero la impronta de Freud ha calado más hondo, revolucionado más contestatariamente y con mayor alcance la historia de la especialidad.

¿Y la persona de Freud, tan polémica, tan vilipendiada, tan despreciada, tan alabada, tan venerada? Digamos al pasar una sola palabra ¿cuánto de todo ello no son sino deseos, esperanzas, rabias, desengaños, desilusiones, celos, envidias de nosotros, sus seguidores y detractores? ¿H abrá que achacarle a Freud nuestras propias insuficiencias, nuestros anhelos insaciables y siempre presentes de contar con un sujeto que nos consuele y de seguridad, tanto en la ciencia como en la vida? Como apunta N ietzsche, somos "aún niños iEternamente niños!"

Sí, Freud fue el maestro de la sospecha. N os hizo dudar de nuestros dogmas más inconmovibles sobre la realidad pero sobre todo de nuestra interioridad, nos conminó a la veracidad consigo mismo, y así nos desterró del paraíso terrenal de nuestra infancia para sumergirnos sin consideración alguna, salvo para lo que él valoraba como la verdad, en la inhóspita existencia que le está asignada a cada cual, "mi pesimismo me parece un resultado; el optimismo de los demás, una hipótesis". Su sospecha fue intransable, pero jamás cargada de rencor ni resentimiento, "sólo comprensible dentro de una cierta integridad y prolijidad". De ahí proviene la modestia frente a su propia producción y su futuro científico, modestia no siempre apreciada y de la cual siempre estuvo consciente: "cuanto más grandiosas son las perspectivas, más reducida es la seguridad y más apasionada la parcialidad de los hombres".

Correspondencia:

Gustavo Figueroa C.

E-mail: gufigueroa@vtr.net 